\title{
Drag and Wake Modification of Axisymmetric Bluff Bodies Using Coanda Blowing
}

\author{
J. B. Freund* and M. G. Mungal $\uparrow$ \\ Stanford University, Stanford, California 94305
}

\begin{abstract}
This work investigates the ability of Coanda jet blowing to modify the base pressure of a cylindrical body aligned axially in a flow, and thereby, produce overall drag reduction. It is found that blowing through one or two slot jets concentric to the outer body circumference can significantly influence the entire base flow region. The recirculating wake is eliminated and is replaced by freestream fluid entrained by the Coanda blowing. Base pressure rises significantly and leads to drag reduction of up to $30 \%$ beyond the thrusting action of the Coanda jet. A comparison between the power savings through drag reduction and the power requirement of the Coanda jet demonstrates that net benefits are attainable at certain body geometries and flow conditions. By judiciously selecting the jet blowing velocity, it is possible to produce a nearly flat wake velocity profile requiring little net power.
\end{abstract}

\section{Introduction}

D RAG reduction of immersed bodies is a subject with a long history, leading to the early concept of streamlining. The net drag force on a body may be considered the sum of viscous drag and pressure drag forces. For streamlined aerodynamic and hydrodynamic bodies, the pressure drag is small, and current research is directed towards the application of laminar flow control (e.g., suction), turbulent viscous drag reduction [e.g., riblets and large eddy breakup devices (LEBUs)], and the use of nonlinear aerodynamics for induced drag reduction (e.g., winglets or crescent wing planforms). For bluff bodies, on the other hand, streamlining is usually not an option for reducing drag because the bluff shape is often dictated by other constraints. This situation is particularly true for trucks, buses, and most automobiles. For bluff bodies then, where pressure drag dominates, drag reduction is primarily through base flow modification, including flow separation control using airfoils, the use of plates, cavities, base bleed, and suction/blowing.

Bluff bodies may be considered of two general classifications - high and low aspect ratio. The former may be modeled as bodies of large span relative to a characteristic height, and are generally two-dimensional in nature. Examples would be the classic cylinder in crossflow, or a symmetric airfoil with a thick, blunt trailing edge. Drag reduction for such bodies has been performed ${ }^{1-3}$ with drag reductions of up to $64 \%$ reported in the literature.

Low aspect ratio bodies have also been studied. Such bodies are characterized by three-dimensionality or axisymmetry, with a sphere being the classic example. Other examples would be cylinders of rectangular or circular cross section aligned axially in the flow direction. Work on drag reduction of such bodies has been reported in Refs. 4-12. A variation of these studies would include inclined base regions such as fast-back automobiles and cargo transport aircraft. During the energy crisis of the seventies, renewed interest in vehicle drag led to many important new findings which are summarized in the books

Received Sept. 17, 1991; presented as Paper 92-2705 at the AIAA 10th Applied Aeroc namics Conference, Palo Alto, CA, June 22 24, 1992; revision received April 20, 1993; accepted for publication April 20. 1993. Copyright (C 1992 by J. B. Freund and M. G. Mungal. Published by the American Institute of Aeronautics and Astronautics, Inc. , with permission.

Graduate Student. Mechanical Engineering Department.

$\dagger$ Associate Professor, Mechanical Engineering Department. Senior Member AIAA. of Sovran et al.,$^{13}$ Hucho, ${ }^{14}$ and the references contained therein. For the specific case of truck drag reduction, a general consensus from such work is that while considerable drag reduction was accomplished by changes to the front end of such bodies (e.g., fairings), there have been few practical solutions to the problem of drag reduction associated with the aft end of the body, i.e., base drag reduction. Recently, Modi et al. ${ }^{15}$ have demonstrated that judiciously positioned spinning cylinders can lead to drag reductions of as much as $27 \%$ for a tractor/trailer configuration. It is also claimed that the power requirements are negligible for such a system.

In this work, we attempt to use Coanda jet blowing ${ }^{16 \cdots 18}$ to affect the base flow of a bluff body, and therefore, produce drag reduction. For simplicity we have chosen a cylinder of circular cross section with its axis aligned in the flow direction. Drag coefficients, base pressures, wake profiles, and power requirements are described below. There is some similarity between the present work and the earlier body of work on blowing on airfoils ${ }^{11 . .22}$ for circulation control; however, the airfoil studies generally emphasized increases in lift and drag that would be desirable for STOL applications. Lockwood ${ }^{2.3}$ applied Coanda blowing to circular cylinders for possible STOL applications with Ghee and Leishman ${ }^{2+}$ reporting on unsteady Coanda blowing applied to the circular cylinder. An excellent review of related work can be found in the text by Chang, ${ }^{25}$ with more recent summaries in Refs. 26-28.

The Coanda jet has also seen recent renewed interest. Wood and Roberts ${ }^{2)}$ have used leading-edge blowing and the Coanda effect to demonstrate flow control on delta wings. Juvet and Reynolds ${ }^{30}$ have demonstrated the Coanda jet's ability to control round jet flows. Commercially, the Coanda effect has been used in combustion applications such as the BP INDAIR flare $^{31}$ for oil refineries. Aerospace applications include the new McDonnell-Douglas Corporation helicopter design, the NOTAR (for No TAil Rotor), ${ }^{32}$ in which the conventional tail rotor is replaced by Coanda jet blowing around the tail boom.

\section{Experimental Details}

The model used to test the possible drag reducing qualities of the Coanda jet is shown schematically in Fig. 1. It consisted of a $24-\mathrm{cm}-\left(9 \frac{1}{2}-\right.$ in.-) long by $10.8-\mathrm{cm}-\left(4 \frac{1}{4}-\right.$ in.-) diam cylinder with a matching streamlined $10.2-\mathrm{cm}-(4-i n .-)$ long nosepiece. Several different geometries were tested on the body base. One rear had a $0.30-\mathrm{mm}$ - (0.012-in.-) circumferential slot (left insert, Fig. 1) to which could be attached four back plates to study the effect of radius of curvature upon the base flow and 




Fig. 1 Sketch of model showing detail of Coanda jet and various body rears.

drag modification. Three of the back plates were cut with 9.5-, 12.7-, and 25.4-mm ( $\frac{3}{8-}, \frac{1}{3}-$, and 1-in.) radii, and the fourth plate cut square with no radius for use as a comparison. A second rear was designed and cut with two concentric blowing slots (right insert, Fig. 1). It was based upon a $12.7-\mathrm{mm}-$ ( $\frac{1}{2-\text { in.-) }}$ radius corner, but included a secondary blowing slot designed to meet the flow from the first slot tangentially at $45 \mathrm{deg}$ along the 90-deg arc. The outer slot width was 0.25 $\mathrm{mm}(0.010 \mathrm{in}$.$) , and the inner slot width was 0.19 \mathrm{~mm}(0.007$ in.). The outer slot of this rear could be taped off leaving only the inner slot at $45 \mathrm{deg}$. This was done to determine whether or not the ambient flow could close itself with a "boat tailing" effect ${ }^{3.3}$ over the first half of the turn and then be entrained by the Coanda blowing for the second half. Care was taken to ensure that the radii were tangent to the jet blowing direction for all geometries. The specific design of the Coanda jet exits followed the general rules outlined in Rodman et al. ${ }^{3+}$

The body was held centrally in the $45.7-\times 45.7-\mathrm{cm}(18-$ $\times 18$-in.) test section of a closed circuit wind tunnel. Drag (or thrust) of the model was transmitted by a $12.7-\mathrm{mm}-$ ( $\frac{1}{2}$-in.-) o.d. tube, bolted internally to the body, to a force transducer located under the test section via a precision pivot and moment arm. This tube also served as the pathway for directing the pressure tubing out of the body. Stagnation, static, and base pressures (Fig. 1) were read on a standard bank of manometers.

Parallel to the support tube was the air supply tube for Coanda blowing. Regulated compressed air entered an internal manifold in the model, then passed through eight $12.7-$ mm- ( $\frac{1}{2}-$ in.-) diam holes, a section of foam (for turbulence management), and out through the rear body slot or slots to form the Coanda jet. Both of the tubes leading from the floor of the test section to the body were encased in a single hardwood airfoil to reduce their parasitic drag. The maximum flow possible with the present setup was approximately $0.85 \mathrm{~m}^{3 /}$ $\min \left(30 \mathrm{ft}^{3} / \mathrm{min}\right)$, but this value varied with rear geometry due to variable pressures drops in the body caused by different slot widths. The volumetric flow was measured with a calibrated Meriam laminar flow element. Coanda flow velocities could be regulated between 0 and about $150 \mathrm{~m} / \mathrm{s}$ (maximum jet velocity also varied with the slot area of the given back), while tunnel speeds used were $20,30,40$, and $50 \mathrm{~m} / \mathrm{s}$, the latter being the maximum tunnel speed; based on body diameter, the corresponding Reynolds numbers varied from 1.4 $\times 10^{5}$ to $3.6 \times 10^{5}$.

An important detail in this work is that the incoming pressurized air induces moments which might affect the drag measurements. To minimize these moments caused by the incoming flow, a special design was adopted whereby the air entered normal to the axis of the support pivot, before being internally redirected to the air supply tube. In addition, a static calibration in which the flow was discharged perpendicular to the line of action on the pivot and force transducer was used to eliminate any residual moments due to the air supply system. Overall, we estimate the measured drag to be good to within $5 \%$. No corrections are made for tunnel blockage effects in the results shown below.

\section{Results}

The variable parameters in the data accumulation were: the back installed on the body ( $\frac{3}{8}-i n$. radius, $\frac{1}{2}$-in. radius, 1 -in. radius, square, double slots, and inner slot acting at $45 \mathrm{deg}$ ). the Coanda jet flow rate, and the tunnel velocity. Raw data at each condition included the effective drag measured on the force transducer, the pressure profile on the back face of the body, and wake velocity profiles taken behind the body at a distance of one body diameter using a Kiel probe. Three special cases were examined more closely: 1) that of zero Coanda jet flow, 2) Coanda jet flow such that the jet flow velocity was twice the ambient velocity, and 3) Coanda jet flow such that the combined effects of jet thrusting and drag 
reduction placed the body at a condition of zero net drag (i.e. the force transducer experiences the same loading as it would with the body in still air). Results are described next.

\section{Drag Coefficients}

Figure 2 shows the immediate benefit of the Coanda effect using a base plate with curvature over a base plate with no curvature for the specific case of zero tunnel velocity. This dimensional plot shows the measured thrust vs the Coanda jet velocity. In this and all subsequent plots, the symbols represent measured data which have been joined by straight line segments. At jet velocities exceeding approximately 50 $\mathrm{m} / \mathrm{s}$, the additional benefit of the Coanda jet, shown by the difference between the radiused back and square back curves, is apparent. The line labeled "theory" is the theoretical thrust of a round jet of equal exit area and velocity as the existing slot jet and is shown for comparison. Note that beyond $50 \mathrm{~m} / \mathrm{s}$ the theoretical curve differs from the square back curve as significant base recirculation (and low pressure) is induced by the peripheral slot configuration of the jet. Since this is the case, the square back offers a poor comparison for judging the performance of the Coanda effect and alternate means of qualifying the result will be developed later.

Figure 3 a shows the drag coefficient $C_{D}$ of the body plotted as a function of jet velocity normalized by the ambient flow velocity. A clear and expected reduction in $C_{D}$ is seen in the graph. Plotted are the square back, the one slot $\frac{1}{2}$-in.-radius back, and the two slot back for a tunnel velocity of $30 \mathrm{~m} / \mathrm{s}$. The square back is seen to never achieve zero drag; the curved backs show better results than the square back, and do indeed achieve zero drag. Two slot blowing is seen to be superior to single slot blowing. At a speed ratio of about 2 , the drag coefficient has been halved for the two slot configuration. At zero jet velocity there is a noticeable drag reduction dependent upon base geometry. Figure $3 \mathrm{~b}$ shows the effect of changing the tunnel speed from 20 to $50 \mathrm{~m} / \mathrm{s}$ for two slot back. There is an improvement in performance with increasing speed suggesting some (weak) Reynolds number effect on the results. At higher tunnel speeds, we were unable to supply the flow rate required for high jet to tunnel speed ratios. Figure $3 c$ compares the results of using a single inner slot, single outer slot, or both slots at $30 \mathrm{~m} / \mathrm{s}$. The single inner slot is seen to lead to a curious large increase in drag not found in the other two cases; we have no explanation for this effect. The declining drag coefficients seen in Fig. 3 are unclear concerning the actual drag reducing capabilities of Coanda blowing owing to the difficulty in separating the reduction of the drag coefficient due to "true" drag reduction from that due to thrusting of the jet.



Fig. 2 Measured thrust force for the square and $\frac{1}{2}$-in. radius back with outer slot at zero tunnel velocity.
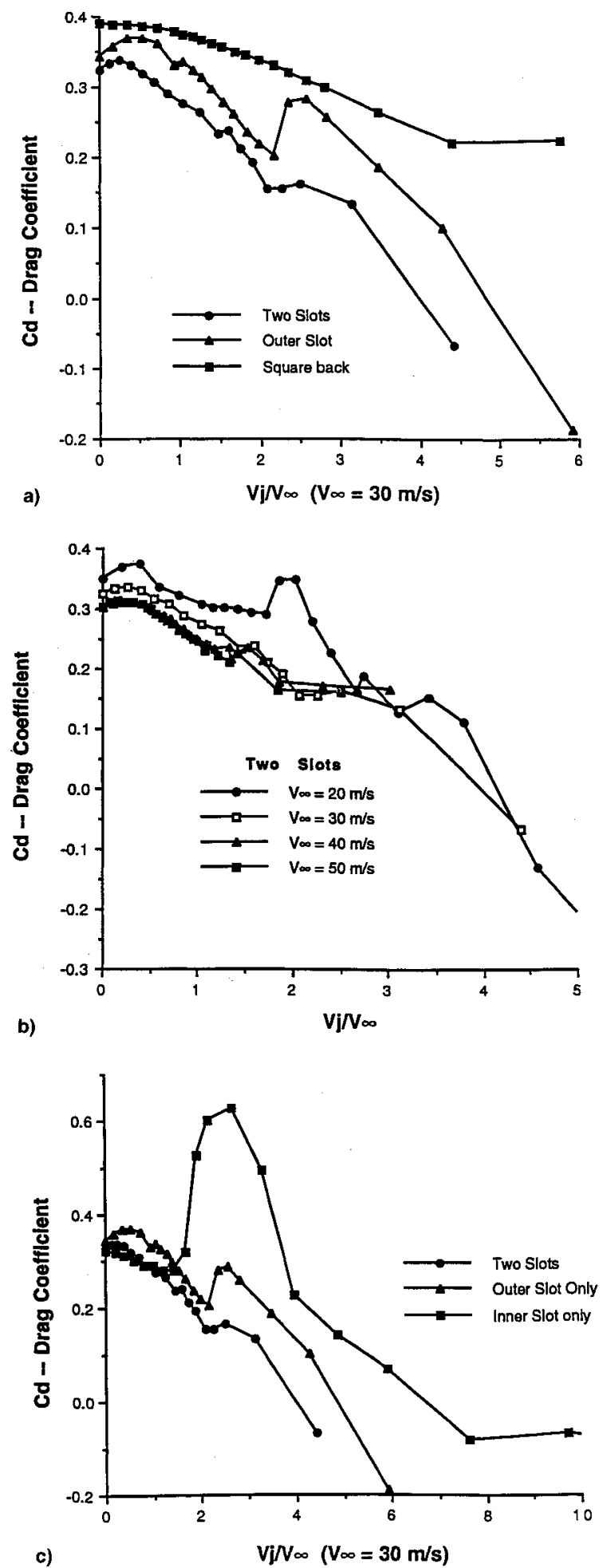

Fig. 3 Drag coefficient as function of jet to tunnel velocity ratio: a $V_{\%}=\mathbf{3 0} \mathrm{m} / \mathrm{s}$, two slots, $V_{,}=20,30,40,50 \mathrm{~m} / \mathrm{s}$, two slots; and c) $V_{2}=30 \mathrm{~m} / \mathrm{s}$, single inner slot, single outer slot, two slots.

A clearer presentation of the results is a dimensional plot (Fig. 4) comparing the change in the load cell measurements at nonzero tunnel speed (the thrust + drag reduction) to the change in load cell measurement at zero tunnel speed (the thrust only). The two-slotted back returned the overall best results, as we shall see again later in a power consumption analysis, and was therefore selected for this plot. There is a visible benefit gained when the Coanda effect combines with a nonzero ambient flow. The actual drag benefit is the difference between the nonzero ambient velocity and zero ambient velocity curves. There is a $25 \%$ drag benefit for the 


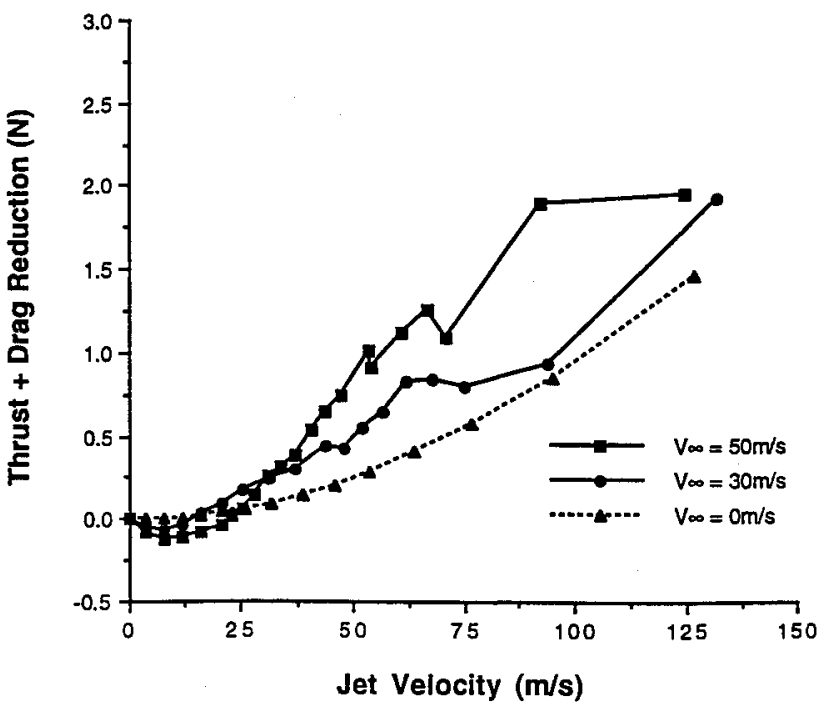

Fig. 4 Thrust and drag reduction (i.e., the net effect of the Coanda jet on the body) at tunnel speeds 0,30 , and $50 \mathrm{~m} / \mathrm{s}$. Test section conditions at atmospheric pressure and room temperature.

$30 \mathrm{~m} / \mathrm{s}$ tunnel speed case with jet velocity twice the ambient flow velocity, and a $30 \%$ drag benefit for the $50 \mathrm{~m} / \mathrm{s}$ tunnel speed case with the same jet flow criterion. Geometries other than the two slot showed less significant results. The single outer slot radiused backs all produced nearly identical data, indicating a very weak dependence upon radius of curvature over the range tested. At $30 \mathrm{~m} / \mathrm{s}$, the $\frac{1}{2}$-in.-radius back showed a $20 \%$ benefit, but this was less than and extended over a smaller range of jet flow velocities than did the two slot back. The single inner slot proved ineffective as a drag modifier. All results shown above were for laminar boundary layers along the body; tripping the boundary layer downstream of the nosepiece produced essentially the same results.

\section{Power Requirements}

While drag reductions and power savings occur, a certain amount of power is required to generate the Coanda jet. In order to gain better insight into the overall power benefits of base Coanda blowing, we define an idealized dimensionless number, the power ratio

$$
\mathrm{PR}=\left(D_{0}-D\right) V_{\infty} /\left(\frac{1}{2} \dot{m}_{j} V_{j}^{2}\right)
$$

where $D$ is the drag force of the body and the subscript 0 refers to the no jet blowing condition. The numerator represents the drag power saved (change in drag force $\times$ freestream velocity) as a result of blowing, while the denominator represents the ideal power required to supply the Coanda jet $\left(\frac{1}{2} \times\right.$ mass flow rate $\times$ jet velocity squared $)$, assuming an initial state of zero velocity. If instead of using the Coanda effect one were to ideally discharge the jet fluid downstream, then the change in drag force $\left(D_{0}-D\right)$ would simply be the jet thrust $\dot{m}_{j} V_{j}$. Substituting this into the above expression yields the PR for a conventional thrusting jet:

$$
\mathrm{PR}_{c}=2 V_{\nsim} / V_{j}
$$

Comparisons will be made below between the actual performance using the Coanda jet (PR) and calculated performance assuming a conventional jet discharge $\left(\mathrm{PR}_{c}\right)$.

Figures $5 \mathrm{a}$ and $5 \mathrm{~b}$ present the power ratio results for several of the cases tested. Figure 5 a shows results for the double slotted configuration at 30 and $50 \mathrm{~m} / \mathrm{s}$. Figure 5 b shows results for the outer slot, inner slot, and square back, respectively, at $30 \mathrm{~m} / \mathrm{s}$. It should be noted in these plots that we are comparing the measured PRs against those calculated assuming no losses $\left(\mathrm{PR}_{c}\right)$. The measured power ratios exceed the con-
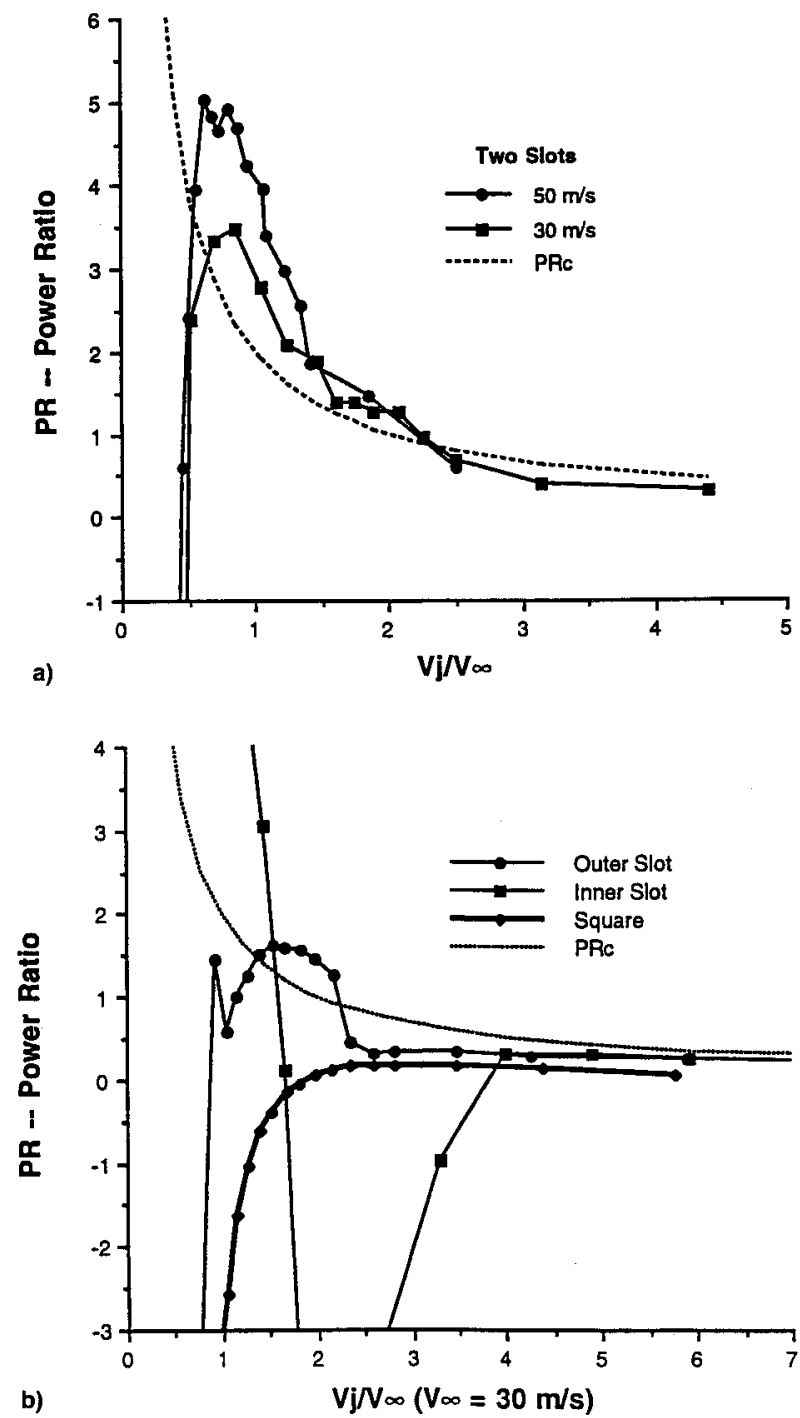

Fig. 5 Power ratio as defined in text for several body geometries and flow conditions: a) $V_{\mathrm{r}}=30 \mathrm{~m} / \mathrm{s}$, two slot back; $V_{\%}=50 \mathrm{~m} / \mathrm{s}$, two slot back and b) $V_{\%}=30 \mathrm{~m} / \mathrm{s}, \frac{1}{2}-$ in. radius with single slot back; $V,=30$ $\mathrm{m} / \mathrm{s}$, inner slot at $45 \mathrm{deg} ; V_{\%}=30 \mathrm{~m} / \mathrm{s}$, square back.

ventional power ratios over ranges on several of the plots, and represent beneficial performance of the Coanda jet. Best results are for the two slotted geometry, and there is a Reynolds number effect causing somewhat better performance at higher Reynolds number values. At very low jet velocities the PR becomes very unstable as its denominator varies as $V_{i}^{3}$. hence, at low jet velocities, we see the PR approaching from either a very high or very low value.

\section{Base Pressure and Flow}

Pressure profiles taken along the base of the body indicate the effectiveness of the Coanda blowing strategy at closing the low pressure wake along the rear face, thus decreasing the pressure component of the drag force. Readings taken from seven static pressure taps positioned on the rear face, spaced at $6.35-\mathrm{mm}(0.25-\mathrm{in}$.) intervals from the body centerline toward the body edge, are presented in Fig. 6. On the plot, data from the two slotted base is presented and the tunnel speed was $30 \mathrm{~m} / \mathrm{s}$. The case with no blowing (circles) clearly shows the low pressure region at the base of the body: such a profile is typical of any such bluff body. ${ }^{35}$ Under the condition that the jet velocity is twice the ambient velocity (the squares), it can be seen that the low base pressure region has been very nearly eliminated. On the PR plots it is apparent that at this point the power benefits are above those predicted for an idealized non-Coanda jet. At a high blowing condition. 


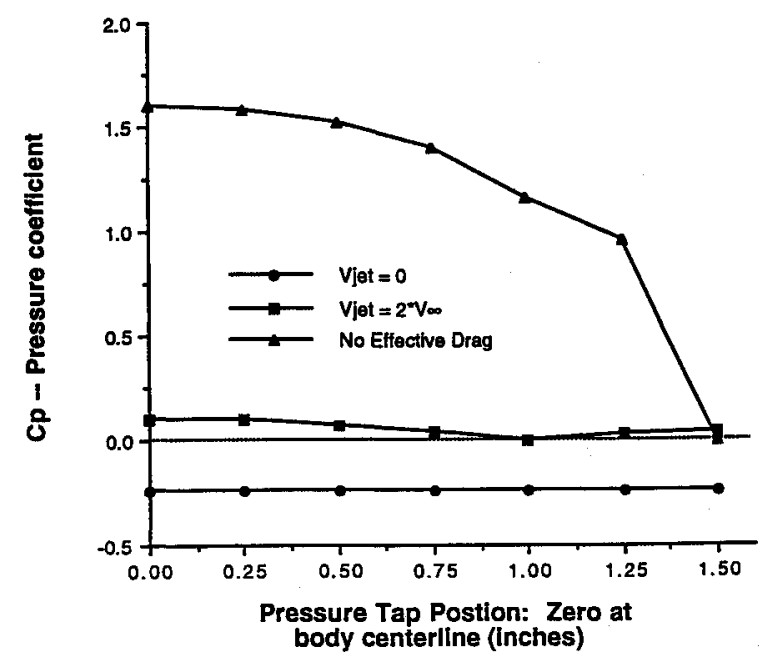

Fig. 6 Static pressure distribution on back face for two slot back: squares- $V_{j}=2 V_{,}$; triangles-zero net drag flow; circles-no flow.

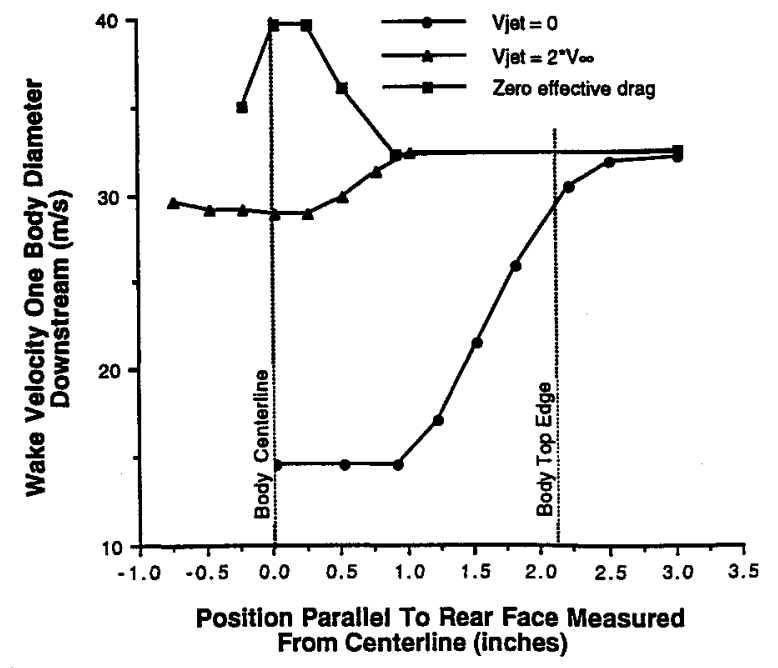

Fig. 7 Velocity profile one body diam downstream of model with two slot back and $\dot{V}_{\%}=30 \mathrm{~m} / \mathrm{s}$.

that of no effective drag, it can be seen on the pressure profile plot that the wake low pressure region has been replaced by a large pressure recovery region, indicating a large thrusting force, large enough to cancel all drag forces on the body. The pressure coefficient is seen to exceed unity over a significant region of the base. We were unable to instrument the radiused portion of the body, but would expect that the pressure at this location to be subambient as is required by the Euler $n$ equation. ${ }^{22}$ It is of interest to note that the square back always produced increased suction in the base region with jet blowing, consistent with the inability to produce zero net drag.

Velocity profiles were taken at a distance of one body diameter downstream using a Kiel probe. Results for the two slot body at a tunnel speed of $30 \mathrm{~m} / \mathrm{s}$ are presented in Fig. 7 . For the condition of no blowing we observe a typical momentum deficit as would be expected behind a bluff body of this sort. However, at the condition of jet velocity being twice the ambient velocity the wake is nearly eliminated; the width of the wake has been greatly decreased and the absolute velocities vary by only $10 \%$ across the entire rear of the body. This is a direct consequence of the strong entraining capability of the Coanda Jet. Upon reaching the condition of zero effective drag, the wake has lost most of its momentum deficit and has developed a centrally located momentum excess. Similar profiles may also be developed using the single outer slot arrangement, but the overall power equation for the body is not as favorable. The single slot body rear at any of the three

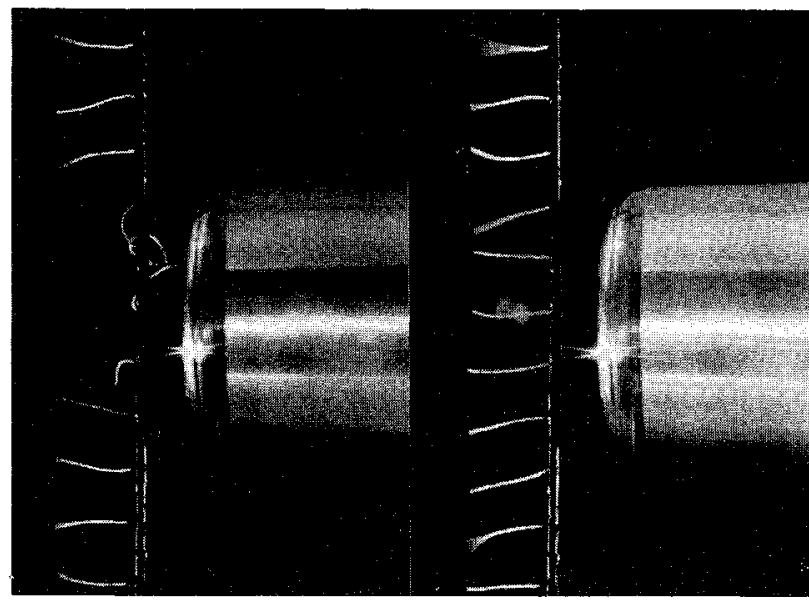

Fig. 8 Photograph of $\frac{3}{7}$-in.-long tufts $\frac{1}{2}$-in. downstream of model. Left no blowing; right, blowing for zero drag case; two slots, $V_{\%}=$ $30 \mathrm{~m} / \mathrm{s}$.

radii tested proved capable of closing the wake, but less efficiently than the two slot body rear.

Figure 8 shows flow visualization results using tufts. The left photograph shows a $\frac{1}{2511}-\mathrm{s}$ exposure of the flow $12.7 \mathrm{~mm}$ $\left(\frac{1}{2}\right.$ in.) behind the body. The recirculating flow is clearly evident. The right photograph shows the same situation, but with the Coanda jet at the zero drag flow velocity. The wake is completely eliminated and, from Fig. 7, has in fact been replaced by a central jet. Figure 9 shows corresponding photographs while using a single freestream tuft. The Coanda jet's entrainment appetite and ability to turn the freestream flow, thus filling the base region, are clearly revealed.

\section{Discussion}

There are several possible applications and extensions of the result presented here. First, Coanda blowing could offer drag reduction for trucks, cars, transport aircraft, and other semibluff bodies for which streamlining the rear end is impractical. In the case of a truck such as a tractor/trailer configuration, the number of sides that needs to be blown, the effects of corners, the ground effect, as well as the effects of crosswind are worthy of investigation. Second, a Coanda propulsion system can be designed to be self-contained within a body in which fluid may be sucked from the surroundings and blown out the rear in a Coanda jet, taking advantage of the thrust for propulsion of the body and the drag reducing qualities of the jet for efficiency. Third, Coanda blowing may be used to eliminate or minimize the wake signature of a body using little net power.

As a point of possible practical interest it should also be noted that in a real vehicle the jet fluid could be entrained from the front and sides of the vehicle at or near the ambient flow velocity, reducing the power requirement for bringing the flow to twice the ambient velocity, while increasing the intake momentum drag; new power ratios would have to be defined which incorporate this fact. In addition, our comparisons of $P R$ are made to a $P R_{c}$ which do not reflect losses that a conventional jet system must also sustain. Such a correction might extend the range of beneficial operation. The power ratios we have calculated assume an initial state of zero velocity; inlet momentum drag was not at play in our experiments as the air was supplied independently of the freestream.

Our results show that increasing the number of slots from one to two produced a significant improvement in performance. This may be related to a better distribution of the high momentum fluid in the Coanda jet. A further increase in the number of slots for a body of the size tested is impractical owing to machining constraints. The height of the slot was also not varied in this work, but should be investigated 




Fig. 9 Photograph of single tuft parallel to model. Left, no blowing; right, blowing for zero drag case; single outer slot, $V_{\%}=30 \mathrm{~m} / \mathrm{s}$.

in the future. Clearly, it would be beneficial to test Iarger scale devices with a larger number of slots and to determine the optimum number, placement and height. Multiple slots would also appear of interest in existing applications where the tendency has been to utilize single slots. There also appears to be a small Reynolds number effect in our results, with better performance at higher Reynolds number. Testing of a larger scale body would also be beneficial from this point of view.

The significant entraining and mixing ability of the Coanda jet was seen in Fig. 9. While this feature has been used in the BP INDAIR flare, it appears that the present configuration with multiple slots together with a central jet affords the possibility of increased flexibility in mixing and combustion applications.

Finally, the experiments reported here may be related to current ideas on convective vs absolute instability. ${ }^{36.37}$ In this approach, the stability of a shear layer may be absolutely unstable for reverse flow, but convectively unstable for forward flow; consequently, the shear layer development occurring just past the separation line on a bluff body might be impacted, depending upon the shape and direction of the mean velocity profile. Clearly, Coanda blowing affects the profile of the separating shear layer and could therefore affect the wake development and drag of the bluff body.

\section{Conclusions}

This work has sought to investigate the ability of Coanda jet blowing to modify the base pressure and wake of a bluff body, and hence produce overall drag reduction. It is found that multiple slot blowing is superior to single slot blowing. Also, blowing with a jet velocity from 1 to 2 times the ambient velocity produces a beneficial drag modification of the body. The recirculating wake is eliminated and is replaced by freestream fluid entrained by the Coanda jet. Base pressure rises significantly. It is also possible to produce negative drag (i.e., thrust) with this configuration. By judiciously selecting the jet blowing velocity, it is possible to produce a nearly flat wake velocity profile. Application to larger scale bodies and to rectangular bodies warrants further investigations. The significant entraining ability of the Coanda jet suggests possible combustion applications.

\section{Acknowledgments}

This work was sponsored by a grant from the Stanford Office of Technology Licensing, Stanford, California. The design effort of $\mathbf{K}$. Mahesh during the early phases of the work and the machining skills of $\mathrm{R}$. Birch are greatly appreciated.

\section{References}

'Frey, K.. "Verminderung des Stroemungswiderstandes von kopern durch leitflaechen," Forschung Ing. Wesen, March/April, 1933, pp. $67-74$

'Tanner, M., "A Method for Reducing the Base Drag of Wings with Blunt Trailing Edge," Aeronautical Quarterly, Feb. 1972, pp. 15-23.

'Rodriguez, O., "Base Drag Reduction by Control of the ThreeDimensional Unsteady Vortical Structures," Experiments in Fluids, Vol. 11, 1991, pp. 218-226.

${ }^{+}$Goldschmied, F. R., "Integrated Hull Design, Boundary-Layer Control, and Propulsion of Submerged Bodies," Journal of Hydronautics, Vol. 1, No. 1, 1967, pp. 2-11.

"Parsons, J. S., Goodson, R. E., and Goldschmied, F. R., "Shaping of Axisymmetric Bodies for Minimum Drag in Incompressible Flow," Journal of Hydronautics, Vol. 8, No. 3, 1974, pp. 100-107.

"Kentfield, J. A. C., "Short, Multi-Step, Afterbody Fairings," Journal of Aircraft, Vol. 21, No. 5, 1984, pp. 351, 352.

${ }^{7}$ Kentfield, J. A. C., "Drag Reduction by Means of Controlled Separated Flows," AIAA Paper 85-1800, Aug. 1985.

"Quass, B., Howard, F., Weinstein, L., and Bushnell, D., "Longitudinal Grooves for Bluff Body Drag Reduction," AIAA Journal, Vol. 19 , No. 4, 1981, pp. 535-537.

"Howard, F. G., and Goodman, W. L., "Axisymmetric Bluff-Body Drag Reduction Through Geometrical Modification," Journal of Aircraft, Vol. 22, No. 6, 1985, pp. 516-522.

"Sakamoto, H., Tan, K., and Haniu, H., "An Optimum Suppression of Fluid Forces by Controlling a Shear Layer Separated from a Square Prism," Journal of Fluids Engineering, Vol. 113, June 1991, pp. $183-189$.

"Powers, S. G., "Flight Tests of External Modifications Used to Reduce Blunt Base Drag," Journal of Aircraft, Vol. 28, No. 8, 1991, pp. $517-525$

"Okamoto, S., and Uemura, N., "Effect of Rounding Side-Corners on Aerodynamic Forces and Turbulent Wake of a Cube Placed on a Ground Plane," Experiments in Fluids, Vol. 11, 1991, pp. 58-64.

I.Sovran, G.. Morel, T., and Mason, W. T., Jr. (eds.), Aerodynamic Drag Mechanisms of Bluff Bodies and Road Vehicles, Plenum Press, New York, 1978

${ }^{1+H u c h o, ~ W .-H . ~(e d .), ~ " A e r o d y n a m i c s ~ o f ~ R o a d ~ V e h i c l e s: ~ f r o m ~ F l u i d ~}$ Mechanics to Vehicle Engineering," Butterworth-Heinemann, London, 1987.

${ }^{15}$ Modi, V. J., Fernando, M. S. U. K., and Yokomizo, T., "Moving Surface Boundary-Layer Control: Studies with Bluff Bodies and Application," AIAA Journal, Vol. 29, No. 9, 1991, pp. 1400-1406.

${ }^{16}$ Newman, B. G., "The Deflection of Plane Jets by Adjacent Boundaries-Coanda Effect," Boundary Layer and Flow Control, Its Principles and Application, Pergamon, London, 1961, pp. 232264.

${ }^{7}$ Wille, R., and Fernholz, H., "Report on the First European Mechanics Colloquium, on the Coanda Effect," Journal of Fluid Mechanics, Vol. 23, No. 4, 1965, pp. 801-819.

i"Reba, I., "Applications of the Coanda Effect," Scientific American, June 1966, pp. 84-92.

"Englar, R. J., "Circulation Control for High Lift and Drag Generation on STOL Aircraft," Journal of Aircraft, Vol. 12, No. 5, 1975, pp. $457-463$

"Davenport, F. J., and Hunt, D. N., "Deflection of a Thick Jet by a Convex Surface: a Practical Problem for Powered Lift," AIAA Paper 75-167, Jan. 1975.

'Englar, R. J., and Huson, G. G., "Development of Advanced Circulation Control Wing High-Lift Airfoils," Journal of Aircraft, Vol. 21, No. 7, 1984, pp. 476-483.

"Bevilaqua, P. M., "Design of a Supersonic Coanda Jet Nozzle," AIAA Paper 84-0333, Jan. 1984.

"Lockwood, V. E., "Lift Generation on a Circular Cylinder by Tangential Blowing from Surface Slots," NASA TN D-244, May 1960 .

${ }^{2+}$ Ghee, T. A., and Leishman, J. G., "Unsteady Circulation Control Aerodynamics of a Circular Cylinder with Periodic Jet Blowing," AIAA Journal, Vol. 30, No. 2, 1992, pp. 289-299.

${ }^{25}$ Chang, P. K., Control of Flow Separation: Energy, Conservation, Operational Efficiency and Safety, Hemisphere, Washington, DC, 1976

"Tanner, M., "Reduction of Base Drag," Progress in Aerospace Sciences, Vol. 16, No. 4, 1975, pp. 369-384.

${ }^{27}$ Fiedler, H. E., and Fernholz, H.-H., "On Management and Control of Turbulent Shear Flows," Progress in Aerospace Sciences, Vol. 27. 1990, pp. 305-387.

${ }^{24}$ Gad-el-Hak, M., and Bushnell, D. M., "Separation Control: Review," Journal of Fluids Engineering, Vol. 113, March 1991, pp. $5-30$.

${ }^{20}$ Wood. N. J., and Roberts, L., "Control of Vortical Lift on Delta Wings by Tangential Leading-Edge Blowing," Journal of Aircraft, 
Vol. 25, No. 3, 1988, pp. 236-243.

${ }^{33}$ Juvet, P. J., and Reynolds, W. C., "A Remarkable CoandaControlled Jet Flow," Open Forum Poster Presentation W-4, Seventh Symposium on Turbulent Shear Flows, Stanford Univ., Stanford, CA, Aug. 1989.

"Weinberg, F. J., "The First Half-Million Years of Combustion Research and Today's Burning Problems," Fifteenth Symposium (International) on Combustion, The Combustion Inst., Pittsburgh, PA, 1974, pp. 1- 17 .

"Logan, A. H., "No Tail Rotor (NOTAR) Design," Veriflite, Vol. 35. No. 3, 1989, pp. 28-30.

3.Mair, W. A., "Reduction of Base Drag by Boat-Tailed Afterbodies in Low Speed Flow," Aeronautical Quarterly, Vol. 20, 1969, pp. $307-320$.

${ }^{i+}$ Rodman, L. C., Wood, N. J., and Roberts, L., "An Experimental Investigation of Straight and Curved Annular Wall Jets," Dept. of Aeronautics and Astronautics, Stanford Univ., Rept. JIAA TR-79, Stanford, CA, 1987.

${ }^{35}$ Hoerner, S. F., Fluid-Dynamic Drag, published by the author, Brick Town, NJ, 1965.

"Huerre, P., and Monkewitz, P. A., "Absolute and convective instabilities in free shear layers," Journal of Fluid Mechanics, Vol. 159. 1985 , pp. $151-168$.

${ }^{37}$ Strykowski, P. J., and Niccum, D. L., "The Stability of Countercurrent Mixing Layers in Circular Jets," Journal of Fluid Mechanics, Vol. 227, 1991, pp. 309-343.

\title{
Introduction to Dynamics and Control of Flexible Structures
}

\author{
JOHN L. JUNKINS AND YOUDAN KIM
}

This new textbook is the first to blend two traditional disciplines: Engineering Mechanics and Control Engineering. Beginning with theory, the authors proceed through computation, to laboratory experiment, and present actual case studies to illustrate practical aerospace applications. SDCMO: Structural Dynamics and Control MATLAB $\otimes$ Operators and a set of exercises at the end of each chapter complement this important new teaching tool. A 100-page solutions manual is available for the convenience of the instructor.

Contents: Mathematical Background: Matrix Analysis and Computation; Stability in the Sense of Lyapunov: Theory and Applications; Mathematical Models of Flexible Structures; Design of Linear State Feedback Control Systems; Controllability and Observability of Finite-Dimensional Dynamical Systems; Design of Linear Output Feedback Control Systems

1993, 470 pp, illus, Hardback, ISBN 1-56347-054-3

AIAA Members $\$ 54.95$, Nonmembers $\$ 69.95$, Order \#: 54-3(945)

Place your order today! Call 1-800/682-AIAA

\section{UAIAA}

American Institute of Aeronautics and Astronautics

Publications Customer Service, 9 Jay Gould Ct., P.O. Box 753, Waldorf, MD 20604 FAX 301/843-0159 Phone 1-800/682-2422 9 a.m. - 5 p.m. Eastern
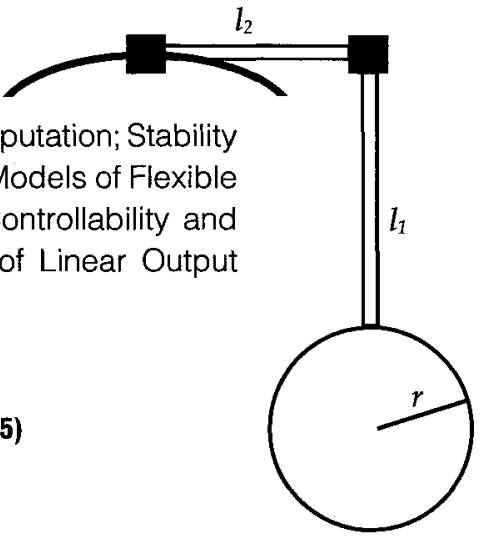

Sales Tax: CA residents, $8.25 \%$; DC, $6 \%$. For shipping and handling add $\$ 4.75$ for $1-4$ books (call for rates for higher quantities). Orders under $\$ 100.00$ must be prepaid. Foreign orders must be prepaid and include a $\$ 20.00$ postal surcharge. Please allow 4 weeks for delivery. Prices are subject to change without notice. Returns will be accepted within 30 days. Non-U.S. residents are responsible for payment of any taxes required by their government. 